\title{
Maleta Didática - Máquina de corrente contínua no ensino do eletromagnetismo para o nível médio
}

Didactic Case - Direct current machine in the teaching of electromagnetism to high school

\author{
Murilo Araújo Santos ${ }^{*}$, Daniela de Oliveira Maionchi² \\ ${ }^{1}$ Instituto Federal de Educação, Ciência e Tecnologia de Mato Grosso, Sinop, MT, Brasil. \\ ${ }^{2}$ Universidade Federal de Mato Grosso, Cuiabá, MT, Brasil.
}

Received on April 23, 2021. Revised on May 25, 2021. Accepted on May 31, 2021.

\begin{abstract}
Este artigo propõe a construção de uma maleta didática utilizando uma máquina de corrente contínua para auxiliar o processo de ensino-aprendizagem na área do eletromagnetismo para o ensino médio, tanto nas disciplinas de física como na de máquinas elétricas. O protótipo desenvolvido é usado nas aulas práticas de eletromagnetismo e de máquinas elétricas do curso técnico em Automação Industrial e Eletromecânica, ambos integrados ao nível médio. A maleta foi construída utilizando uma máquina de corrente contínua semelhante a de liquidificadores domésticos de duas velocidades. Os enrolamentos formam conectados a bornes para facilitar as conexões do circuito através de conectores banana. Circuitos elétricos, tensão e corrente elétrica, lei de indução de Faraday e algumas características funcionais são alguns temas discutidos, na perspectiva da Teoria da Aprendizagem Significativa, com o apoio desta maleta.
\end{abstract}

Palavras-chave: Eletromagnetismo, lei de Faraday, máquina de corrente contínua, ensino médio.

\begin{abstract}
This article proposes the construction of a didactic case using a direct current machine to assist the teachinglearning process in the area of electromagnetism for high school, both in the disciplines of physics and in electrical machines. The developed prototype is used in the practical classes of electromagnetism and electrical machines of the technical course in Industrial Automation and Electromechanics, both integrated to high school. The case was built using a direct current machine similar to domestic two-speed blenders. The windings are connected to terminals to facilitate circuit connections through banana connectors. Electrical circuits, voltage and electric current, Faraday's law of induction and some functional characteristics are some topics discussed, from the perspective of the Theory of Meaningful Learning, with the support of this case.
\end{abstract}

Keywords: Electromagnetism, Faraday's law, dc machine, high school.

\section{Introdução}

Observa-se um certo distanciamento dos alunos em relação à disciplina de Física no ensino médio. Os discentes relatam dificuldades em entender os fenômenos físicos que acontecem na natureza, sejam eles de cunho mecânico, térmico ou eletromagnético. Essas dificuldades podem causar frustrações e promover o desinteresse no estudo desta disciplina. Além disso, há uma necessidade dos cidadãos serem cientificamente alfabetizados para lidar com problemas de escala global como as mudanças climáticas, a edição gênica e o suprimento de energia [1]. Desta forma, torna-se imprescindível a constante busca por conhecimento a fim de promover uma melhor qualidade de vida a nossa espécie.

A disciplina de eletromagnetismo possui características abstratas por sua própria natureza que envolve a presença de campos e potenciais. O domínio desses conceitos requer que o aluno construa modelos mentais flexíveis e testáveis a fim de relacioná-los com o

\footnotetext{
*Endereço de correspondência: murilo.santos@snp.ifmt.edu.br
}

conhecimento prévio, condição essencial para consolidar o assunto em sua estrutura cognitiva de maneira significativa. O conceito de campo elétrico ou magnético envolve o espaço tridimensional e componentes contraintuitivos, alheios a sua realidade. Nesse contexto, o aluno dispõe de poucas analogias do assunto com o seu cotidiano e isto prejudica seu aprendizado sobre o tema [2]. A demonstração prática associada com discussões sobre o assunto colaboram com o desempenho acadêmico de estudantes 3 .

Para tentar mitigar essas dificuldades, os professores podem utilizar recursos didáticos extras, não usuais, além de lousa e giz como parte da metodologia de ensino. Como exemplo, as atividades práticas costumam aumentar o interesse e, consequentemente, aprimorar o desempenho acadêmico e reduzir as faltas dos estudantes 4. Algumas companhias oferecem produtos que podem ser experimentos, demonstrações ou outras atividades práticas sobre os mais variados assuntos da física. Entretanto, esses equipamentos geralmente são custosos e, portanto, a aplicação nas escolas fica restrita. Este trabalho propõe a construção de um 
recurso didático de baixo custo que visa auxiliar o ensino de eletromagnetismo utilizando a máquina de corrente contínua.

\section{O Eletromagnetismo Clássico e a Máquina de Corrente Contínua}

A abordagem do eletromagnetismo no ensino médio não deve ser necessariamente extensa e complexa. Os conceitos fundamentais que devem ser enfatizados e são suficientes para entender os fenômenos eletromagnéticos são descritos a seguir.

A força magnética $\vec{F}$ está no cerne teórico do funcionamento de um motor elétrico. Essa força surge quando um corpo carregado com uma carga $Q$ se move com uma velocidade $\vec{v}$ dentro de um campo magnético de densidade de fluxo $\vec{B}[5$, esquematizado na Figura 1 É importante salientar que quando a carga estiver se movimentando na mesma direção do campo magnético, independente do sentido, a força magnética resultante sobre ela será nula. A intensidade, direção e sentido dessa força pode ser calculado através da seguinte equação,

$$
\vec{F}=Q(\vec{v} \times \vec{B})
$$

Tendo em vista que a força magnética é resultado de um produto vetorial, podemos dizer que esta é sempre perpendicular ao plano que contém os vetores $\vec{v}$ e $\vec{B}$. Isso faz com que, além da força $\vec{F}$, a aceleração $\vec{a}$ também seja sempre perpendicular ao movimento da carga elétrica. $\mathrm{O}$ vetor $\vec{a}$ descreve apenas a mudança de direção do vetor $\vec{v}$, mantendo o módulo deste constante. Desta forma, não há variação de energia cinética no corpo carregado e, consequentemente, não há transferência de energia do campo magnético para a carga elétrica. Este fenômeno implica que a força magnética não desenvolve trabalho. O conceito de carga em movimento nos remete à noção de corrente elétrica. A corrente elétrica é um fluxo de cargas elétricas movendo de um lugar a outro. É definida pela razão da quantidade de carga $\Delta Q$ que atravessa uma determinada área em um determinado tempo $\Delta t$ podendo ser calculada através da Equação (2). No sistema internacional de unidades, a corrente elétrica é dada em ampères.

$$
I=\frac{\Delta Q}{\Delta t}
$$

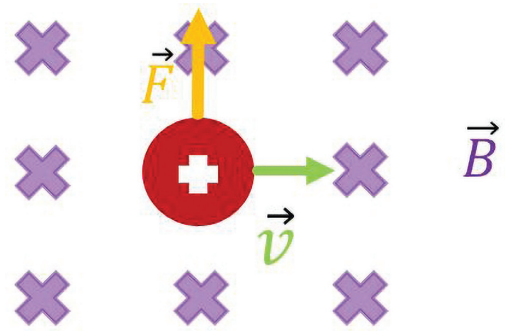

Figura 1: Força magnética exercida em uma carga $Q$.

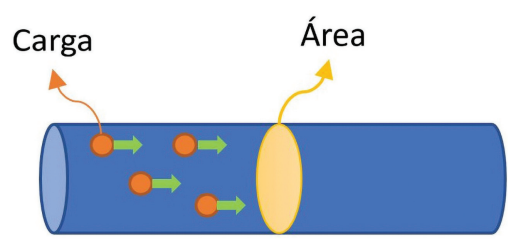

Figura 2: Esquema simplificado de cargas em movimento dentro de um condutor cilíndrico qualquer.

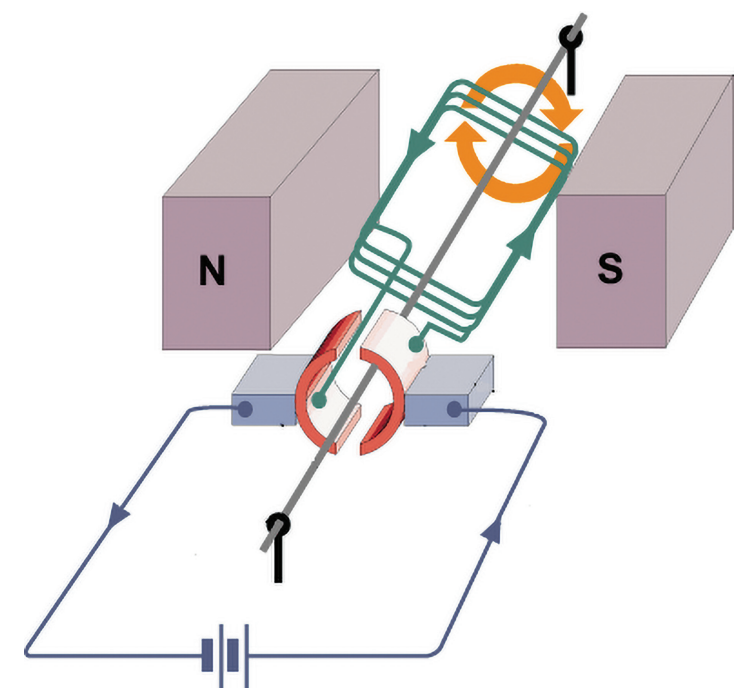

Figura 3: Esquema construtivo da máquina de corrente contínua - adaptado de [6].

Esse movimento está esquematizado na Figura 2

É possível reescrever a Equação (1) da seguinte forma [5],

$$
\vec{F}=I \vec{L} \times \vec{B}
$$

onde $I$ é a corrente, $\vec{L}$ é o vetor comprimento de um fio orientado no sentido da corrente e $\vec{B}$ é o vetor densidade de fluxo magnético. Essa força aparece nos condutores que formam as espiras mostrada na Figura 3 Em máquinas elétricas, o conjunto dessas espiras é denominado enrolamento de armadura.

Uma máquina de corrente contínua é um conversor eletromecânico de energia. Isto significa que este pode converter energia elétrica em energia mecânica. Nesta configuração, é chamado de motor elétrico. No entanto, ela também pode converter energia mecânica em energia elétrica; nesta circunstância, é denominado gerador elétrico. No caso desta máquina, o campo magnético pode ser originado por ímã permanente, exemplificado na Figura 3 ou por uma outra bobina externa chamada de enrolamento de campo. Sua direção e sentido estão esquematizados pelos polos magnéticos $\mathrm{N}$ (norte) e $\mathrm{S}$ (sul). Quando o enrolamento de armadura do motor estiver posicionado na vertical, a força induzida no condutor superior será igual em módulo com a do condutor inferior, resultando torque $\tau$ nulo. Neste momento, 
é necessária a inversão do sentido da corrente dentro do enrolamento da armadura. Para isso, a injeção de corrente na bobina do rotor é feita através de um anel comutador.

Caso o motor tenha enrolamento de campo, é possível energizar esse motor de diversas formas. Na excitação independente, são necessárias duas fontes de tensão. O enrolamento de armadura e o enrolamento de campo são ligados através destas respectivas fontes e não há conexão elétrica entre os dois circuitos. Há a possibilidade de ligar o enrolamento de armadura e de campo em série, de forma que a corrente que circulará nos enrolamentos será a mesma. Pode-se ligar os enrolamentos em paralelo (shunt), aplicando o mesmo valor de tensão em seus terminais. É possível também estabelecer uma conexão dita composta, onde uma parcela do enrolamento de campo é colocada em série com o enrolamento de armadura. Esta ligação, entretanto, requer um ponto de derivação no enrolamento de campo. Trata-se de uma característica construtiva específica e não é encontrada em todos os motores de corrente contínua.

Essas diversas conexões possibilitam que o motor apresente características de funcionamento distintas tendo como sua principal mudança a relação entre torque $\tau$ e velocidade de rotação $\omega$.

\section{Construção da Maleta Didática}

A maleta didática é constituída por uma caixa retangular e, em seu interior, foram fixadas duas placas de acrílico, a máquina de corrente contínua e um bocal para lâmpadas. Nestas placas, foram embutidos os bornes e a chave de dois estados, conforme mostrado na Figura 4. Esses bornes foram utilizados para facilitar as conexões do circuito através de conectores "banana".

Inicialmente, foi elaborado um projeto com desenhos da maleta didática a fim de observar as dimensões necessárias da caixa e das placas em acrílico, bem como as identificações dos bornes. Essas placas possuem $7 \mathrm{~mm}$ de espessura e foram cortadas à laser. Não é

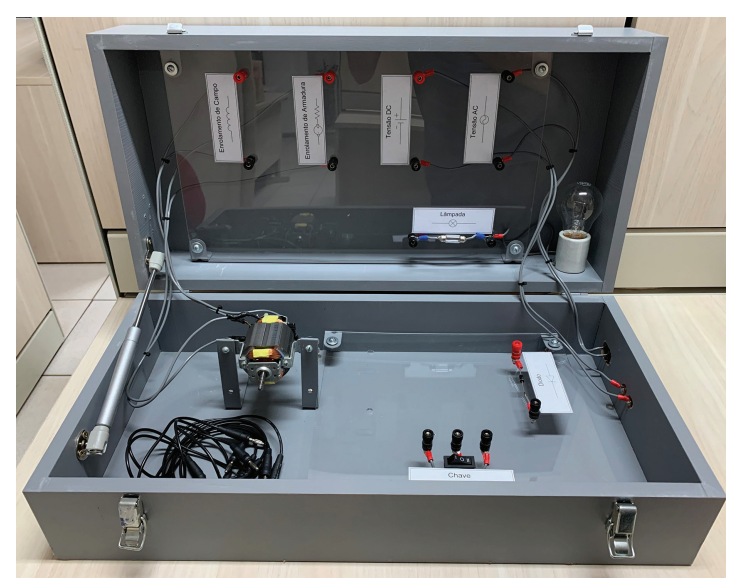

Figura 4: Foto da maleta didática. indicado o uso de furadeiras com brocas para realizar os furos, pois estas podem trincar a placa de acrílico, danificando permanentemente o material. Deve-se então remover a película protetora da placa e inserir os bornes. Para realizar a fixação das placas e da máquina no interior da maleta, foram utilizadas chapas metálicas e parafusos com porcas, comumente encontradas em lojas de marcenaria.

Os terminais dos enrolamentos de campo e armadura da máquina de corrente contínua foram descontinuados com auxílio de um alicate de corte. Foram soldados à condutores de $1,5 \mathrm{~mm}^{2}$ e então protegidos eletricamente com fita isolante. Esses condutores foram clipados com um terminal do tipo "olhal" e então conectados aos respectivos bornes. Este procedimento também foi realizado para efetuar a ligação do bocal da lâmpada incandescente $(40 \mathrm{~W})$, a chave de 2 estados, o diodo e a lâmpada incandescente de $5 \mathrm{~W}$. A fim de se obter uma estética mais agradável, as alimentações elétricas provenientes das fontes de corrente contínua e alternada foram feitas através de terminais localizados na lateral direita da maleta didática.

Este produto foi desenvolvido em forma de maleta com o intuito de ser prático e móvel. Desta forma, é possível levar o produto para diversas salas de aula, sem grandes dificuldades, mesmo para escolas que não possuam um laboratório disponível para auxiliar os estudantes. Para que as demonstrações possam ocorrer, é necessária a utilização de fontes de tensão contínua e alternada, um multímetro para mensurar os parâmetros elétricos como tensão e corrente elétrica e uma furadeira para servir como máquina primária na operação geradora. A fonte de tensão contínua utilizada é fabricada pela INSTRUTHERM, modelo FA-3003. Possui uma tensão máxima de $32 \mathrm{~V}$ e corrente elétrica de $3 \mathrm{~A}$, podendo fornecer no máximo $100 \mathrm{~W}$ de potência. Essa tensão pode ser controlada através de dois seletores (ajuste fino e grosso). Já a fonte de tensão alternada é desenvolvida pela JNG, modelo TDGC2 de $1 \mathrm{kVA}$. Sua tensão pode ser selecionada através do dial que vai de $0 \mathrm{~V}$ a $140 \mathrm{~V}$ e corrente elétrica máxima de $8 \mathrm{~A}$. A máquina de corrente contínua é fabricada pela Keli Motors, modelo HC5440M127-BD-CCA. Sua tensão nominal é de $127 \mathrm{~V}$ e corrente de 4,72 A, podendo oferecer no máximo $600 \mathrm{~W}$. Para demonstração da ação geradora, foram utilizadas duas lâmpadas incandescentes de 12 V (5 W e 40 W). A chave de dois estados e o diodo são utilizados para demonstração do funcionamento de um liquidificador doméstico de duas velocidades, muito comum em domicílios brasileiros.

Cabe aqui salientar que nas demonstrações, são utilizadas tensões inferiores a $50 \mathrm{~V}$ (corrente alternada) e $120 \mathrm{~V}$ (corrente contínua) sendo classificadas, segundo a Norma Regulamentadora 10 - Segurança em Instalações e Serviços em Eletricidade, como extra-baixa tensão [7]. A Norma Regulamentadora 16, que trata sobre atividade e operações perigosas, não considera um trabalho periculoso "atividades ou operações em instalações 
ou equipamentos elétricos alimentados por extra-baixa tensão" [8], não oferecendo riscos importantes à saúde e segurança dos usuários.

\section{Metodologia: Possíveis Abordagens}

\subsection{Conceitos de circuitos elétricos: série e paralelo}

Geralmente, quando se trabalha com eletrodinâmica no ensino médio, os conceitos de série e paralelo são limitados à teoria. Sem a atividade prática, o aluno acaba não tendo uma oportunidade de relacionar esses conceitos com a práxis.

A Figura 5 mostra os terminais do enrolamento de campo e enrolamento de armadura e a fonte de tensão contínua presentes no interior da maleta didática. Para realizar a ligação paralela entres os enrolamentos e a fonte de tensão contínua, deve-se ligar o borne 1-3-5 e 2-4-6. Para energizar os enrolamentos do motor em série, ligam-se os terminais 5-3. A corrente flui por dentro do enrolamento da armadura e sai pelo borne 4 e então entra pelo borne 2, segue pelo enrolamento de campo e então sai pelo borne 1 até o outro terminal da fonte de corrente contínua. Essa ligação está demonstrada na Figura 6

\subsection{Utilização do multímetro}

É importante o correto manuseio de instrumentos de medição para aferir parâmetros elétricos como tensão e corrente elétrica. O posicionamento incorreto das ponteiras pode resultar em uma leitura errada ou até mesmo em um acidente.

O voltímetro possui uma resistência interna equivalente muito elevada, na ordem de $10^{7} \Omega$ [ e deve ser ligado em paralelo com o ramo o qual se pretende medir a tensão elétrica. Caso esse instrumento seja conectado em série, o observador leria uma determinada tensão equivocada, além de impossibilitar seu apropriado funcionamento.

Já o amperímetro, que possui uma resistência elétrica interna equivalente muito baixa, deve ser conectado em

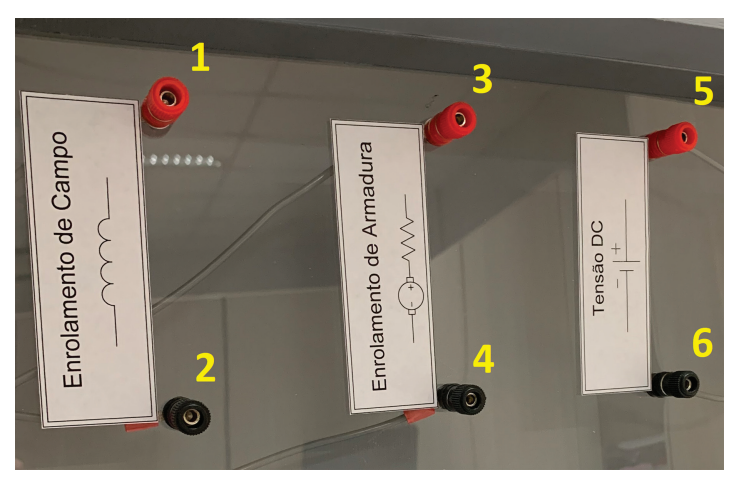

Figura 5: Bornes relativos ao enrolamento de campo, enrolamento de armadura e da fonte de corrente contínua.

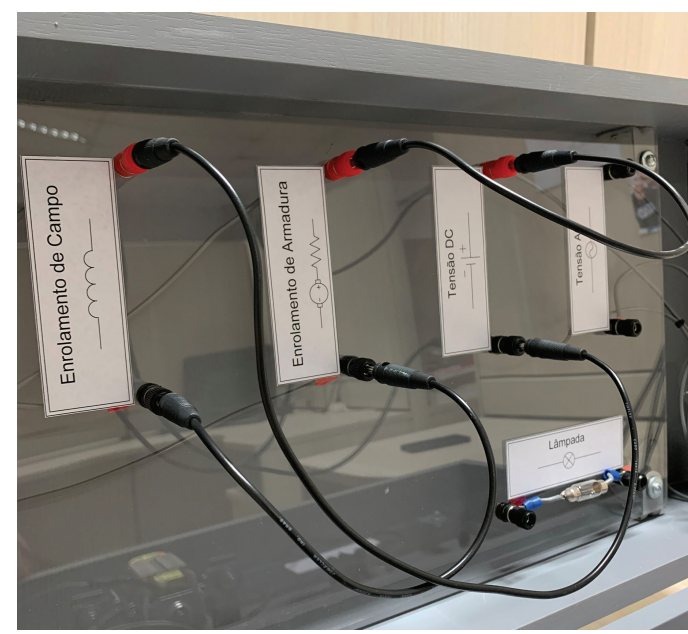

Figura 6: Conexão série dos enrolamentos da armadura e de campo do motor alimentados pela fonte de corrente contínua.

série com o ramo para que uma correta mensuração da corrente elétrica seja realizada. Se esse instrumento for utilizado em paralelo com a fonte de tensão, ocorrerá um curto circuito, podendo causar contratempos como a queima de fusíveis.

A utilização do alicate amperímetro também pode ser demonstrada com auxílio desta maleta didática. Este alicate não consegue medir correntes constantes no tempo, pois seu funcionamento depende de indução eletromagnética. O campo magnético emanado pelo condutor deve ser variante no tempo para que haja uma tensão induzida no circuito do multímetro e, posteriormente, traduzido em valores de corrente elétrica. $\mathrm{O}$ professor poderá ligar a máquina em corrente contínua e alternada (discutido na subseção 4.5 para comparar as aferições realizadas.

Espera-se que o aluno possa, com auxílio do professor, aprender a manusear os equipamentos de medição e realizar aferições corretas de tensão e corrente elétrica. A lei de indução eletromagnética de Faraday também pode ser explorada tendo em vista a possibilidade de demonstração com o alicate amperímetro.

\subsection{Tensão elétrica e velocidade de rotação do motor}

$\mathrm{Na}$ excitação em série, a alteração da tensão de alimentação reflete diretamente na velocidade de rotação do motor. Seu circuito elétrico equivalente está representado na Figura 7

Esse acréscimo de velocidade devido ao acréscimo de tensão terminal pode ser analisado por uma abordagem qualitativa [10]. Assumindo que o motor não possui carga mecânica útil no eixo (o que é o caso no motor presente na maleta didática), o torque de carga, $\tau_{\text {carga }}$, corresponde apenas ao efeito do atrito. Suponhamos que o motor já esteja rodando com velocidade angular constante $(\omega>0)$, então temos que $\tau_{\text {carga }}=\tau_{\text {ind }}$. 


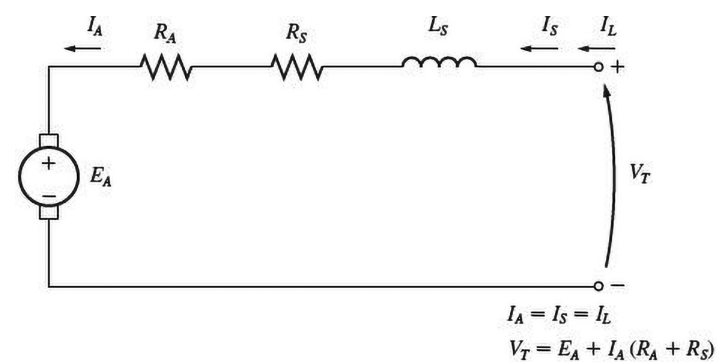

Figura 7: Circuito elétrico equivalente da máquina de corrente contínua na excitação em série - retirado de [10].

A elevação de $V_{T}$ implica num aumento da corrente $I_{L}$, o que leva a um aumento de torque induzido conforme a seguinte equação:

$$
\tau_{\text {ind }}=K \phi I_{L} .
$$

Esse aumento de $\tau_{\text {ind }}$ desequilibra a situação $\tau_{\text {carga }}=$ $\tau_{\text {ind }}$, gerando um torque $\tau$ não nulo que provoca uma aceleração angular $(\alpha)$ a favor do movimento rotacional segundo a seguinte equação,

$$
\tau=I \alpha .
$$

Esta aceleração resulta em um aumento da velocidade de rotação do eixo do motor e, consequentemente, aumento da tensão induzida no enrolamento da armadura. Este fenômeno acontece devido à variação de fluxo magnético que atravessa as espiras do enrolamento do rotor. Essa tensão é descrita no circuito elétrico por $E_{A}$ segundo a equação abaixo,

$$
E_{A}=K \phi \omega_{m},
$$

a qual ajuda a reduzir a corrente $I_{L}$. Esta diminuição de corrente $I_{L}$ reduz o $\tau_{\text {ind }}$ até que $\tau_{\text {ind }}=\tau_{\text {carga }}$ estabilizando a rotação $\omega_{m}$ a uma velocidade mais alta.

Essa dinâmica pode ser apresentada aos alunos com auxílio da maleta didática. Através do monitoramento dos parâmetros de tensão e corrente, é possível constatar essas alterações. Com isso, o subsunçor da eletrodinâmica pode ser estimulado, pois aborda-se o assunto de uma forma não convencional, inserido em um contexto prático.

\subsection{Carga mecânica no eixo do motor e corrente injetada}

O motor de corrente contínua apresenta uma reação quando carga mecânica é adicionada ao seu eixo. Essa reação é observada na corrente que o motor solicita.

Para exemplificar esse fenômeno, será utilizado o motor de corrente contínua com o enrolamento de campo e de armadura ligados em série (excitação em série) conforme mostrado na subseção anterior (Figura 7). A corrente é definida por [10],

$$
I_{L}=\frac{V_{T}-E_{A}}{R_{A}+R_{S}}
$$

Substituindo a Equação (6) em (7), temos,

$$
I_{L}=\frac{V_{T}-K \phi \omega_{m}}{R_{A}+R_{S}} .
$$

Desta forma, pode-se observar que a rotação do motor tem influência na corrente que ele solicita. Quando $\omega_{m}$ diminui, a corrente aumenta e vice-versa. Por exemplo, um motor de $50 \mathrm{HP}$ a $250 \mathrm{~V}$ demanda uma corrente 20 vezes a corrente nominal no momento de sua partida $\left(\omega_{m}=0\right)$ [10. Esta corrente de partida também é denominada por corrente de rotor bloqueado. Os enrolamentos não são dimensionados para suportar esta corrente por um tempo relativamente grande. No momento de sua partida, essa corrente elevada circula por um breve período de tempo, variando de acordo com a potência nominal do motor e a inércia da carga mecânica acoplada ao seu eixo, mantendo assim a temperatura dos condutores em um nível seguro.

No contexto do liquidificador, essa corrente pode ser superior à corrente nominal em algumas situações. Isso acontece quando são adicionadas cargas mecânicas difíceis de serem processadas. A corrente elevada causa uma maior dissipação de energia nos condutores, aumentando sua temperatura. Se essa situação é mantida por um tempo razoável, o verniz que envolve os condutores pode carbonizar e liberar um odor de queimado característico. Além disso, o aumento de temperatura pode levar ao derretimento parcial das bobinas do motor resultando potencialmente em uma interrupção do circuito elétrico. Caso isso ocorra, o motor apresentará características de desempenho prejudicadas, ou até mesmo não funcionar.

Na perspectiva do processo de ensino-aprendizagem, esse fenômeno pode auxiliar a aprendizagem do aluno, tendo em vista que existe um certo conhecimento popular sobre a possibilidade do liquidificador queimar quando este opera com sobrecarga mecânica.

É possível demonstrar esse aumento de corrente utilizando a maleta didática. Primeiramente deve-se ligar o motor em uma tensão reduzida (neste caso, é sugerido utilizar $15 \mathrm{~V}$ ), o que implica em um torque induzido também baixo. Desta forma, é possível segurar o eixo do motor com as próprias mãos, simulando um aumento de carga mecânica, sem comprometer a segurança da demonstração. Ainda, com o auxílio de um amperímetro, pode-se visualizar esse aumento na corrente injetada no motor de corrente contínua.

\subsection{Funcionamento do motor em corrente alternada}

Para alterar o sentido de rotação do rotor, é necessária a inversão da corrente no enrolamento da armadura ou no enrolamento de campo do motor. Caso o sentido dos dois enrolamentos sejam alterados simultaneamente, o rotor permanecerá com o sentido de rotação inalterado.

Quando o motor é ligado em série, a corrente será a mesma nos dois enrolamentos. Na corrente alternada, 
a inversão do sentido da corrente acontece para os dois enrolamentos simultaneamente. Desta forma, o sentido do torque permanece inalterado. Seu funcionamento pode ser demonstrado utilizando a maleta didática e a sua velocidade de rotação pode ser controlada através do nível de tensão que se estabelece em seus terminais.

Este motor, quando ligado em série, também é chamado de motor universal, pois funciona adequadamente em corrente contínua ou corrente alternada.

\subsection{Circuito retificador de meia onda}

Sabe-se que a redução da tensão eficaz do motor de corrente contínua reduz sua velocidade de rotação. Os liquidificadores domésticos mais comuns possuem duas velocidades de rotação, representados pelas posições 1 e 2. Vale salientar que este motor é conectado à tensão nominal de $127 \mathrm{~V}$ ou $220 \mathrm{~V}$ (AC) dependendo da região no Brasil.

A Figura 8 representa o esquema elétrico utilizado em liquidificadores domésticos. Têm-se, da esquerda para direita, a fonte de tensão alternada, chave de dois estados, o diodo e o motor.

Quando a chave é colocada na posição 1, o motor é alimentado através de um diodo conforme mostrado na Figura 8

O diodo é um dispositivo eletrônico geralmente composto por silício dopado com boro e fósforo que, resumidamente, permite a passagem de corrente apenas em um sentido [11]. Quando é inversamente polarizado, este apresenta resistência elétrica equivalente muito elevada. Desta forma, o motor fica submetido a uma tensão eficaz inferior em comparação à ligação direta, sem diodo. Este circuito que utiliza o diodo para reduzir a tensão eficaz na carga também é denominado circuito retificador de meia onda.

Na posição 2, o motor é ligado em tensão nominal, o que acarreta uma maior velocidade de rotação e maior potência mecânica desenvolvida.

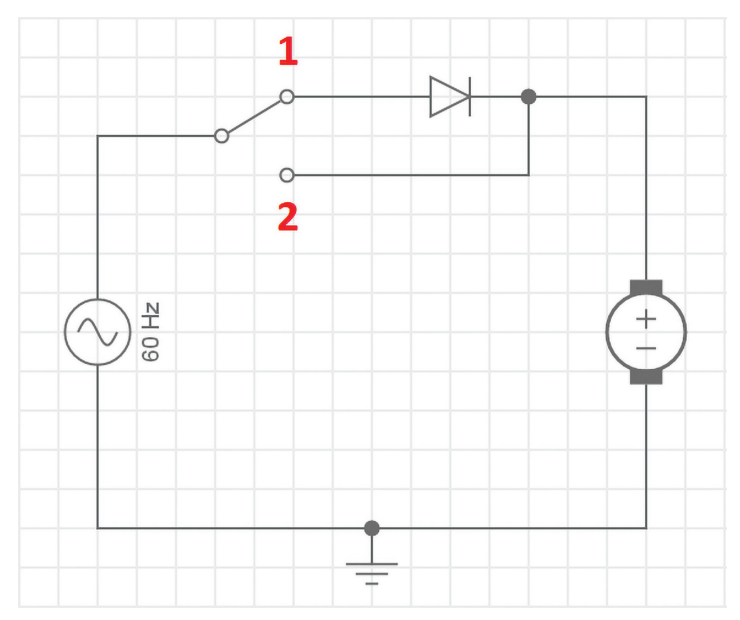

Figura 8: Circuito elétrico equivalente de um liquidificador doméstico com duas velocidades de rotação.

\subsection{Correntes parasitas}

Como visto na subseção 4.5 este motor também pode trabalhar com corrente alternada. Na excitação em série, a corrente que flui no motor é a mesma tanto no enrolamento de campo, quanto no enrolamento de armadura. Esta corrente oscilará de acordo com a frequência da fonte de tensão. No Brasil, esta frequência é $60 \mathrm{~Hz}$.

A corrente alternada que flui no enrolamento de campo induzirá um campo magnético também alternado no circuito magnético do motor. Sabe-se que um campo magnético que varia no tempo gera um campo elétrico que varia no espaço conforme a seguinte equação de Maxwell,

$$
\nabla \times \vec{E}=-\frac{d \vec{B}}{d t} .
$$

O estator dessa máquina é composto por ligas metálicas, nas quais os elétrons da camada de valência acabam por se desvincular do núcleo, ficando livres. Quando este campo elétrico age sobre esses elétrons livres, há a aparição da seguinte força elétrica,

$$
\vec{F}=Q \vec{E} \text {. }
$$

Os elétrons então começam a circular de forma ordenada no núcleo magnético (rotor e estator) do motor, provocando aquecimento. Este processo é irreversível, diminuindo o rendimento e limitando a potência mecânica desenvolvida pela máquina.

No ensino médio, essas correntes induzidas podem ser explicadas através da lei de indução eletromagnética de Faraday,

$$
F e m=-\frac{d \Phi}{d t},
$$

onde Fem é a força eletromotriz dada em Volts, e $\frac{d \Phi}{d t}$ é a variação de fluxo magnético no tempo. Esse potencial elétrico presente nas chapas metálicas do motor geram corrente conforme a primeira lei de Ohm.

A laminação do núcleo magnético de máquinas elétricas, como motores e transformadores, diminui a intensidade da corrente parasita, acarretando menos perdas e elevando seu rendimento [12]. Essas correntes também são chamadas de correntes de Foucault. Desta forma, a corrente circulante fica suprimida, pois como há menos espaço para sua circulação, a mesma observa uma resistência elétrica equivalente maior, diminuindo a intensidade da corrente elétrica e consequentemente sua potência dissipada.

É possível observar este efeito utilizando a maleta didática. Ligando o motor no mesmo nível de tensão em corrente contínua e em corrente alternada verifica-se uma maior temperatura, em regime permanente, quando este é ligado em tensão alternada.

\subsection{Campo magnético residual}

Os átomos de materiais ferromagnéticos apresentam uma característica reativa quando expostos a campos 
magnéticos externos. Os elétrons desemparelhados sofrem torque e tendem a se alinhar com o campo magnético. Isso pode ser observado no funcionamento de bússolas. A agulha móvel precisa necessariamente estar imantada, ou seja, possuir um campo magnético interno para interagir com o campo magnético terrestre e indicar a direção magnética.

Em um outro exemplo, pode-se observar essa situação quando se coloca um ímã na caixa de ferramentas, próximo a chave de fenda. A chave de fenda se torna imantada e pode assim auxiliar a execução de trabalhos com parafusos.

Essa magnetização perdura por um certo tempo mesmo que a fonte de campo magnético seja removida. Essa magnetização diminui com o aumento da temperatura do material e eventuais choques mecânicos nele aplicado. Essa característica se deve ao chamado campo magnético residual $\left(\vec{B}_{\text {residual }}\right)$. Esse fenômeno pode ser observado com a utilização da maleta didática com a máquina funcionando no modo motor ou gerador.

$\mathrm{Na}$ função motor, deve-se ligar o enrolamento de campo com uma tensão contínua por alguns segundos. A corrente que fluirá pelo enrolamento será contínua, assim como seu campo magnético. Esse campo fará com que os momentos magnéticos dos átomos presentes no núcleo magnético da máquina também sejam alinhados. Cessase a alimentação elétrica do enrolamento de campo, levando sua corrente elétrica a zero. Entretanto, devido à questão inercial, o material ferromagnético que compõe o núcleo continua magnetizado com o $\vec{B}_{\text {residual }}$. Quando o enrolamento de armadura é alimentado com tensão contínua, é possível observar uma aceleração angular de seu eixo, implicando que o campo magnético no interior do motor seja necessariamente diferente de zero.

$\mathrm{Na}$ função geradora, em vez de alimentar o enrolamento de armadura, devemos conectar um voltímetro em seus terminais na menor escala. Ao rotacionar manualmente o eixo da máquina, pode-se observar uma pequena tensão induzida.

\subsection{Função geradora}

A máquina de corrente contínua pode ser utilizada como motor ou gerador. Vale salientar que não é necessária nenhuma alteração construtiva da máquina para isso. Basta observar o fluxo de potência, isto é, quando fornecemos alimentação elétrica a máquina nos fornece potência mecânica (motor). Quando fornecemos potência mecânica no eixo, podemos extrair uma tensão nos enrolamentos da armadura.

Pode ser demonstrado, através do uso da maleta didática, a função geradora da máquina de corrente contínua. Energiza-se o enrolamento de campo, gerando corrente elétrica e, consequentemente, campo magnético que permeará o rotor da máquina. Utilizando uma furadeira como máquina primária, podemos acoplá-la mecanicamente ao eixo da máquina através do mandril. Ao acionarmos a furadeira, o enrolamento de armadura também rotaciona dentro do campo magnético. Isso faz com que a variação de fluxo magnético no tempo seja diferente de zero, gerando uma tensão nos enrolamentos da armadura. Para uma visualização melhor por parte dos alunos, esse enrolamento de armadura é conectado a uma lâmpada incandescente de pequeno porte. É possível observar a relação direta entre a velocidade de rotação e a intensidade luminosa emitida pela lâmpada.

\section{Conclusão}

A atividade prática é uma ferramenta importante no processo de ensino-aprendizagem entre docentes e discentes. Experiências e demonstrações podem ser conduzidas como atividades colaborativas onde a troca de significados seja estimulada pelo professor a fim de facilitar a captação de significados que favoreçam a aprendizagem significativa. Desta forma, o modelo mental acerca de um determinado objeto acaba se tornando mais consolidado e robusto. Eventualmente, este conhecimento desenvolvido pode oferecer fundações a novos assuntos e assim colaborar com o progresso do discente.

O alto custo dos materiais didáticos e os eventuais entraves burocráticos prejudicam a execução de atividades práticas nas instituições de ensino. Diante desses problemas, chegou-se à solução de construir o próprio aparato experimental.

Este trabalho mostra que é possível utilizar um motor de corrente contínua para realizar demonstrações acerca da área do eletromagnetismo. Conceitos de série e paralelo, aferição de grandezas elétricas como tensão e corrente, circuitos elétricos, características de funcionamento do motor e a lei de indução eletromagnética de Faraday podem ser trabalhados com auxílio da maleta didática. Almeja-se que este recurso didático promova o interesse e a curiosidade dos alunos sobre a área do eletromagnetismo clássico.

\section{REFERÊNCIAS}

[1] C. Wieman e K. Perkins, Physics Today 58, 36 (2005).

[2] K. Squire, M. Barnett, J.M. Grant e T. Higginbotham, em: Proceedings of the 6th international conference on Learning sciences (Los Angeles, 2004).

[3] C.H. Crouch, A.P. Fagen, J.P. Callan e E. Mazur, American Journal of Physics 72, 835 (2004).

[4] V.F. Pinto, A.P. Viana e A.E.A. Oliveira, Revista Conexão UEPG 9, 84 (2013).

[5] W.H. Hayt e J.A. Buck, Eletromagnetismo (AMGH Editora, Porto Alegre, 2010), v. 1 p. 260.

[6] J. Magtaan, DC Motor, disponível em: https://c15580 367roboblog.wordpress.com/2017/11/28/dc-motor/ acesso em: 11/02/2021.

[7] MINISTÉRIO DA ECONOMIA, NR 10 - Segurança em instalações e serviços em eletricidade. Brasília, 2019. Disponível em: https://www.gov.br/trabalho/pt-br/ inspecao/seguranca-e-saude-no-trabalho/ctpp-nrs/no rma-regulamentadora-no-10-nr-10 
[8] MINISTÉRIO DA ECONOMIA, NR 16 - Atividade e operações perigosas. Brasília, 2019. Disponível em: https: //www.gov.br/trabalho/pt-br/inspecao/seguranca-e-s aude-no-trabalho/ctpp-nrs/norma-regulamentadora-no $-16-\mathrm{nr}-16$

[9] N. Stojilovic e D.E. Isaacs, Physics Education $\mathbf{5 3}$ 053005 (2018).

[10] S.J. Chapman, Fundamentos de Máquinas Elétricas (AMGH Editora, Porto Alegre, 2013), v. 1.

[11] R.L. Boylestad, Dispositivos Eletrônicos e Teoria de Circuitos (Pearson Education do Brasil, São Paulo, 2013), v. 1 p. 70

[12] P.D. Agarwal, Transactions of the American institute of electrical engineers, Part I: Communication and Electronics 78, 169 (1959). 